San Jose State University

SJSU ScholarWorks

Master's Theses

Master's Theses and Graduate Research

1993

\title{
The effects of vagotomy upon motion-induced conditioned taste aversion and motion-induced emesis in Suncus murinus
}

Cappy Levy

San Jose State University

Follow this and additional works at: https://scholarworks.sjsu.edu/etd_theses

\section{Recommended Citation}

Levy, Cappy, "The effects of vagotomy upon motion-induced conditioned taste aversion and motioninduced emesis in Suncus murinus" (1993). Master's Theses. 635.

DOI: https://doi.org/10.31979/etd.9jud-npya

https://scholarworks.sjsu.edu/etd_theses/635

This Thesis is brought to you for free and open access by the Master's Theses and Graduate Research at SJSU ScholarWorks. It has been accepted for inclusion in Master's Theses by an authorized administrator of SJSU ScholarWorks. For more information, please contact scholarworks@sjsu.edu. 


\section{INFORMATION TO USERS}

This manuscript has been reproduced from the microfilm master. UMI films the text directly from the original or copy submitted. Thus, some thesis and dissertation copies are in typewriter face, while others may be from any type of computer printer.

The quality of this reproduction is dependent upon the quality of the copy submitted. Broken or indistinct print, colored or poor quality illustrations and photographs, print bleedthrough, substandard margins, and improper alignment can adversely affect reproduction.

In the unlikely event that the author did not send UMI a complete manuscript and there are missing pages, these will be noted. Also, if unauthorized copyright material had to be removed, a note will indicate the deletion.

Oversize materials (e.g., maps, drawings, charts) are reproduced by sectioning the original, beginning at the upper left-hand corner and continuing from left to right in equal sections with small overlaps. Each original is also photographed in one exposure and is included in reduced form at the back of the book.

Photographs included in the original manuscript have been reproduced xerographically in this copy. Higher quality $6 " \mathrm{x} 9$ " biack and white photographic prints are available for any photographs or illustrations appearing in this copy for an additional charge. Contact UMI directly to order.

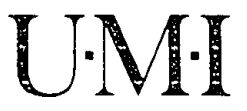

University Microfilms internatıona

A Bell \& Howell Information Company

300 North Zeeb Road. Ann Arbor. MI 48106-1346 USA

313:761-4700 800:521-0600 
Order Number 1954150

The effects of vagotomy upon motion-induced conditioned taste aversion and motion-induced emesis in Suncus murinus

Levy, Cappy Diane Michele, M.A.

San Jose State University, 1993

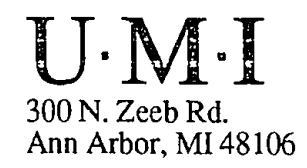


THE EFFECTS OF VAGOTOMY UPON MOTION-INDUCED CONDITIONED TASTE AVERSION

AND MOTION-INDUCED EMESIS IN SUNCUS MURINUS

\author{
A Thesis \\ Presented to \\ the Faculty of the Department of Psychology \\ San Jose State University
}

In Partial Fulfillment

of the Requirements for the Degree

Master of Arts

by

Cappy Levy

August, 1993 


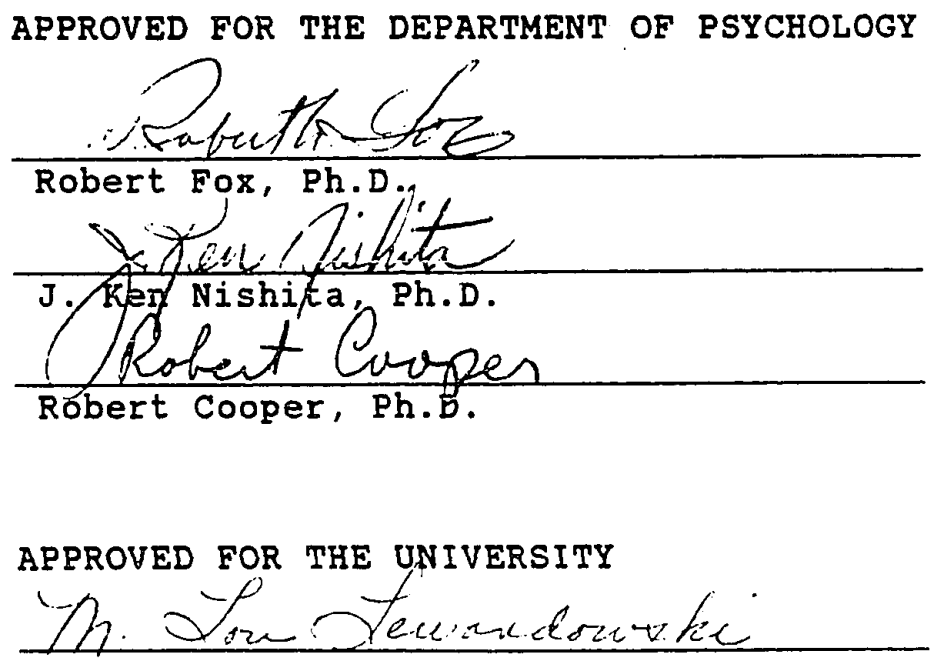




\begin{abstract}
THE EFFECTS OF VAGOTOMY UPON MOTION-INDUCED CONDITIONED TASTE AVERSION AND MOTION-INDUCED EMESIS IN SUNCUS MURINUS by Cappy Levy

Many researchers have been investigating the relationship between conditioned taste aversion (CTA), nausea and vomiting. One theory of this relationship describes CTA, nausea and vomiting as events on a continuum of physiological progression from wellness to extreme sickness. Consistent with this position, it has been assumed that nausea is the putative unconditioned stimulus producing CTA. The role of the vagus nerve was examined in the context of this theory in suncus murinus with motion as the nausea-producing stimulus. Following vagotomy, all animals vomited on one or more exposures to motion, but the CTA produced by this motion was attenuated or delayed. These results show that vomiting may be mediated by a different physiological state than CTA and imply that nausea may contribute to CTR; but perhaps not critically.
\end{abstract}




\section{ACKNOWLEDCOMENTS}

I would like to thank my thesis chair and mentor, Dr. Robert A. Fox, for his numerous constructive comments, professional guidance and virtually endless amount of time, energy and patience spent working toward the completion of this thesis. His vast knowledge and expertise in the area of physiological psychology is of immeasurable value for students, as well as other investigators in this area of specialization who continue to benefit from his research and publications. I am grateful for the opportunity to share in his studies and his guidance with hands-on laboratory techniques in surgery and experimentation. His attention to my education and laboratory training greatly enhanced my experience and qualifications as a graduate student at San Jose State University.

I would also like to thank Dr. Robert Cooper and Dr. J. Ken Nishita for their helpful suggestions and contributions to this thesis project.

Additionally, I would like to thank Karen Pass, for her time and dedicated interest in this project, and Dawn Levy, for her suggestions and loving support in the completion of this project.

This research project was funded in part by the Graduate student Stipend Program, San Jose State University Foundation. 
TABLE OF CONTENTS

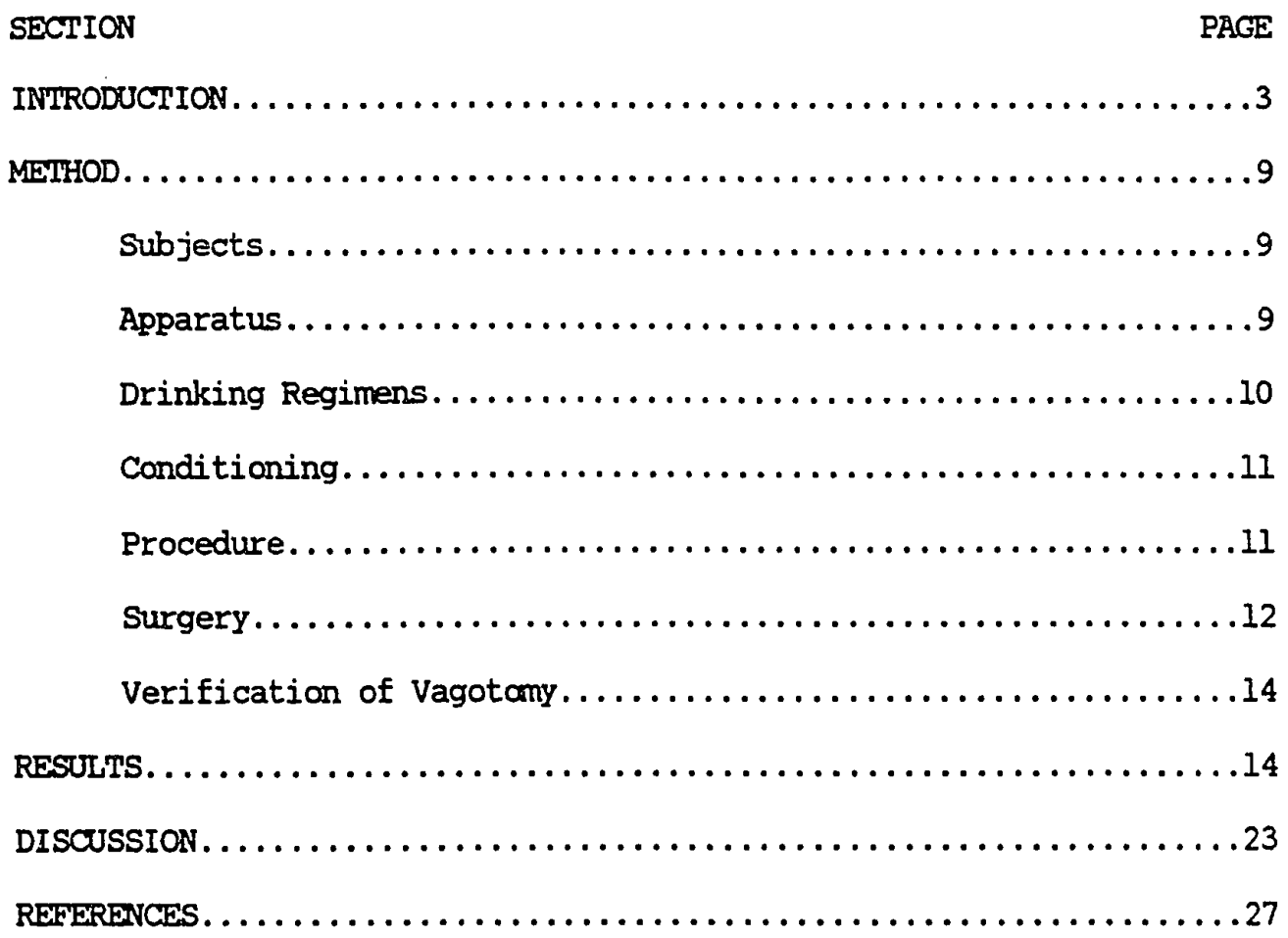


1. Mean intake (with S.E. bars) of saccharin flavored water ( $n=6$ per group) on the 3 conditioning days (Days $1-3$ ) and on the final test day (Day 4) when the animals were not exposed to motion.................

2. Mean intake (with S.E. bars) of saccharin flavored water ( $n=6$ per group) on the 3 days following exposure to motion (Days 2-4) expressed as a percentage of intake on the first day (Dayl) $\ldots \ldots \ldots \ldots \ldots \ldots 21$

3. Mean number of retching/vamiting episodes ( $n=6$ per group) on each of the 3 test days............................. 
Vagotomy, СTA and Emesis

The Effects of Vagotany Upon Motion-Induced Conditioned Taste Aversion and Motion-Induced Emesis in Suncus Murinus

Cappy Levy

San Jose State University

Running head: VAGOTONY, CTA AND EMESIS

Footnotes

Requests for reprints should be sent to Cappy Levy, Department of

Psychology, San Jose State University, San Jose, California 95192-0120. 
Vagotomy, CTA and Emesis

Abstract

Many researchers have been investigating the relationship between conditioned taste aversion (CTA), nausea and vamiting. One theory of this relationship describes CTA, nausea and vomiting as events on a continuum of physiological pragression from wellness to extreme sickness. Consistent with this position, it has been assumed that nausea is the putative unconditioned stimulus producing CTA. The role of the vagus nerve was examined in the context of this theory in sumcus murinus with motion as the nausea-producing stimulus. Following vagotamy, all animals vanited on one or more exposures to motion, but the CTA produced by this motion was attenuated or delayed. These results show that vomiting may be mediated by a different physiological state than CTA and imply thai nausea may contribute to CTA, but perhaps not critically. 
Vagotomy, CTA and Emesis

3

The Effects of Vagotany Upon Motion-Induced Conditioned Taste Aversion and Motion-Induced Enesis In Suncus Murinus

When something is eaten which induces sickness such as nausea and vamiting, that particular food is no longer desirable for consumption. This change in the hedonic value of food is produced by a form of associative learning called conditioned taste aversion (CTA). The formation of CTA offers a unique opportunity to study learning mechanisms, because this aversion can be leamed in only one trial and is readily measurable.

Although CTA is formed as a learned response, identifying the specific unconditioned stimulus (US) that produces this form of learning has been difficult. Many researchers contend that an internal state, nausea, is a feasible candidate for this role because many treatments that produce CTA also produce nausea or emesis. For example, it has been suggested that nausea, pallor, sweating etc. form a continuum of physiological effects leading to emesis (Graybiel, Wood, Miller, \& Cramer, 1968). A CTA may be formed as a learned response with Jauisea as the putative US.

Several empirical findings, however, demonstrate problems with this hypothesis (Gamzu, 1977). One such problem is the fact that studies using radiation as the US have shown that CTA may be formed when nausea is absent or unlikely. For example, CTA can be formed in humans even though patients do not report feeling nauseous or sick (Gerstner, 
1960; Bernstein \& Webster, 1980; Prasad, 1984), and rats have formed CTA even when treated with extrenely low doses of radiation (Garcia, Kimeldorf, \& Hunt, 1961). Despite this evidence, nausea is still regarded as the most likely US in the formation of CTA (Garcia, Lasiter, Bermudez-Rattoni, \& Deems, 1985).

Currently, there is no reliable way to assess nausea in animals. Thus, there has been an interest in using CTA to assess nausea. Accurate assessment of nausea in animals would aid pharmacologists working to improve drugs which relieve nausea associated with motion sickness, chemicals, radiation and other nausea-producing agents. Same researchers have hypothesized that CTA can be used as a subemetic measure of motion sickness in animals which do not vamit (Garcia et al., 1985; Ossenkopp \& Ossenkopp, 1985; Brizzee, Ordy, \& Mehler, 1980; Roy \& Brizzee, 1979).

To support the concept that CTA results fran activation of emetic mechanisms, researchers have investigated whether motion-induced CTA and motion-induced vomiting share the same neural pathways. Because an intact vagus nerve (Fox \& McKenna, 1988) and vestibular system (Hartley, 1977) are essential for the formation of motion-induced CTA, researchers have studied the role of the vagus nerve in both motion-induced CTA and motion-induced emesis.

Some studies on motion-induced CTA and motion-induced vomiting involving the vagus nerve provide support for the continuum conception of CTA, nausea and vomiting, but other studies do not. For examole, 
Vagotomy, СтA and Emesis

both motion-induced CTA (Fox \& McKenna, 1988) and motion-induced emesis (Wang, Chinn, \& Renzi, 1957) are affected by vagotony. Wang et al. (1957) examined the role of abdominal visceral afferents including the vagus nerve in motion-induced sickness in dogs. These investigators found that following vagotany, motion-induced vamiting in dogs was reduced. In another study (Fox \& McKenna, 1988) the role of the vagus nerve in motion-induced CTA was examined, and they found that vagotamy eliminated CTA in rats. In the above two studies, the vagus nerve seemed to be an important mediator of motion-induced CIA and, separately, of motion-induced vomiting.

While research such as this implies that motion-induced CTA and motion-induced vamiting may be related, it remains to be demonstrated whether they are both crucially mediated by the same neural pathways. In studies of both cats (Corcoran, Fox, Brizzee, Crampton, \& Daunton, 1985; Fox, Corcoran, \& Brizzee, 1988) and squirrel monkeys (Roy \& Brizzee, 1979; Wilpizeski \& Lowry, 1987), some animals did not vomit in response to motion, but showed motion-induced CTA. In addition, not all animals which vonited fomed aversions. Findings such as these imply that the mechanisms underlying CTA and vomiting induced by motion are more complex than considered in previous conceptualizations.

Other research on the vagus nerve also has produced conflicting results regarding the mediation of CTA and vomiting by the vagus nerve. For example, if the US is changed from motion to intragastric copper sulfate, the results do not convincingly rule out the notion that CTA 
Vagotomy, CTA and Emesis

and vomiting are both crucially mediated by the vagus nerve. Vomiting research (Wang \& Borison, 1951) showed that the vagus was important in the mediation of vamiting (emesis was reduced by vagotony) and one CTA study (Coil, Rogers, Garcia, \& Novin, 1978) showed that the vagus was important in the formation of CTA (CTA was attenuated by vagotomy). Rabin, Hunt, and Lee (1985), however, showed that the vagus was not crucial in the formation of a CTA produced by intragastric copper sulfate (vagotomy did not reduce or eliminate CTA in rats, in fact CTA was enhanced). Rabin argues this discrepant finding may be explained by delayed stamach emptying caused by vagotony, which could allow the copper sulfate to form a CTA by traveling to the area postrema via the bloodstream. Rabin confinmed this theory by performing area postrema lesions on the rats with vagotomies.

It is possible that other factors, such as differences in procedure, species differences, etc., may account for the discrepant results between studies by Coil et al. (1978) and Rabin et al. (1985). For example, it is known that there is more than one neural pathway involved in Con and vomiting. The weighted contribution of different neural pathways, or how they may interact, may differ among species. The exact involvement of the vagus and how it interacts with other physiological structures in order to produce CTA and vomiting is still largely unknown.

Unfortunately, researchers who have examined whether the vagus is critical in motion-induced CTA, motion-induced nausea and motion-induced 
Vagotomy, CTA and Emesis

vomiting have not often investigated these events within the same species. One reason for the lack of same-species research may be the fact that rodents are capable of forming a CTA, but lack a complete emetic reflex (Hatcher, 1924). While most experiments on CTA have used rodents, research on vaniting, in contrast, has used larger animals such as dogs, cats or monkeys, which have a complete emetic reflex. Because of this, it has been necessary to compare research findings across species, which presents obvious problems in the interpretation of these experiments. Grant (1987) has provided the most complete analysis of this issue, and has concluded that the majority of experiments do not decisively support the emetic-UCS hypothesis, yet none of the discrepant findings provides irrefutable evidence against it.

One animal that may be especially promising for motion sickness research is suncus murinus (Japanese house shrew). Since the shrew is a small mamnal weighing less than $100 \mathrm{~g}$, it is ideal for use in a laboratory setting. This insectivore possesses a complete emetic reflex and vomits in response to motion, as well as other stimuli (Ueno, Miatsuki, â Sāito, 1987; Ueno, Matatsuiki, \& Saito, 1988), but has not previously been used in CTA research.

I propose to examine whether the vagus nerve is one neural pathway which mediates a continuum of effects ranging from CTA to vomiting. Because the shrew has a complete emetic reflex, the role of the vagus nerve in motion-induced CTA and motion-induced vamiting may be investigated concurrently. 
Vagotomy, CrA and Emesis

8

There are a variety of ways to examine CTA in animals. Usually, a novel flavored fluid is associated with an aversive stimulus, then intake of that fluid is measured. If intake significantly decreases in the second test, a CTA has developed. In same tests a one-bottle method is used, in others a two-bottle method is used. In the one-bottle paradigm, if the animal decreases its consumption of the fluid, it concurrently increases its thirst, since less fluid is being consumed. Consequently, increased thirst makes a CTA harder to produce over trials. Two-bottle testing is considered a more sensitive measure of CTA than the one-bottle procedure, since two-bottle tests are based on preference or choice of fluids (Grote \& Brown, 1971). Thus, thirst is not increased over trials.

In an effort to design a more conservative measure of CTA than would be provided by a two-bottle test, a one-bottle test was chosen for use in this experiment. Deprivation conditions inherent in the onestimulus method result in increased variability of conditioning in animals (Dragoin, McCleary \& McCleary, 1971), thus biasing the test against the experimenter. Anchieving statistical significance under these circumstances is harder than if a two-bottle test was used. Statement of the Problem

Two hypotheses were tested in this experiment. Hl: If vagotomy affects the emetic reflex and animals receive a complete vagotomy before introduction to motion, then the formation of a CTA will be significantly impaired. H2: If vagotony affects the emetic reflex, then 
Vagotomy, СTA and Fmesis

the proportion of animals that will vomit will differ significantly between the Vagotomy Group, the Sham Group and the Control Group in this experiment.

\section{Method}

\section{$\underline{\text { Subjects }}$}

Eighteen female shrews were purchased from Clea Inc. of Tokyo. Animals were housed in groups of five or six cintil the beginning of the experiment, then were transferred to individual cages. The colony room was maintained on a 12:12 light:dark schedule (lights on at 08:00

P.S.T.). The shrews had Purina brand Cat Chow and water available at all times, except during conditioning and directly before surgery. Watering schedules during conditioning are explained in the Conditioning section of this paper.

Six animals were assigned randamly to each of the three groups (Vagotony Group, Sham Group, and Control Group). Animals in the Vagotomy Group received a complete gastric vagotomy, animals in the Sham Group received a "sham" surgery (vagal nerve fibers were left intact), and animals in the Control Group did not receive any surgical procedure, but were exposed to the same experimental conditioning as the other animais.

Apparatus

Motion was produced using a Gyrotory shaker table (model G2, from New Brunswick Scientific Co. Inc., Edison, N.J.). The shaker table was adjusted to a frequency of $2 \mathrm{~Hz}$ with $2 \mathrm{~cm}$ range of circular movement in 
Vagotomy, СTA and Emesis

the earth-horizontal plane.

Fluid was provided in pipets that were modified with larger openings at the tip for easier fluid access by the animals. The openings were enlarged by removing the pipet tip and then heating the opening to make it smooth. Consumption was measured directly by reading the graduations on pipets to $1 / 10 \mathrm{ml}$ precision.

Drinking Regimens

Animals were tested 7-8 days following surgery to reduce the possible confounding effects of nerve regeneration prior to testing (Powley, Prechtl, Fox, \& Berthoud, 1983). A restricted drinking regimen prior to surgery was implemented to facilitate transition to restricted intake after surgery. The restricted drinking regimen was achieved by gradually reducing the availability of water over several days ( $12 \mathrm{hr}$ for the first 3 days, $6 \mathrm{hr}$ for the next 2 days, and finally $2 \mathrm{hr}$ for 5 days).

During conditioning the shrews were deprived of water for $22 \mathrm{hr}$. Each shrew was allowed a 10-min drinking opportunity of $2 \%$ weight/volume saccharin solution, after which it received the notions stimilus. Following the motion stimulus the shrews were permitted to drink tap water for a 2-hr period. Prior to surgery, water was available continuously for 3 days to encourage adequate hydration. As a general precaution against aspiration during surgery, food was withheld for 12 hr preceding surgery. The next 7 days after surgery were devoted to readapting the animals to the drinking regimens. Each shrew received 12 
Vagotomy, CTA and Emesis

hr access to water for the first 3 days, $6 \mathrm{hr}$ access to water for the next 2 days, and $2 \mathrm{hr}$ access to water for the last 2 days before conditioning. Taste aversion conditioning began 7-8 days after surgery.

\section{Conditioning}

A one-bottle conditioning procedure may cause a reduction in fluid intake if a CTA is formed to the conditioned stimulus solution. To avoid this, a second drinking opportunity was used. The novel flavored fluid ( $2 \%$ weight/volume solution of Nectasweet brand saccharin) was available during the first drinking opportunity on each test day. Exposure to the saccharin lasted for $10 \mathrm{~min}$. Animals were then permitted free access to tap water for $2 \mathrm{hr}$ in order to facilitate more normal hydration.

Procedure

Animals to be tested were moved approximately $5 \mathrm{~min}$. after lights on from the animal colony to a nearby testing room. Animals were tested two at a time in separate cages. Each shrew was permitted to drink the saccharin solution for î̂ min and then was placed iñ añ iñùividuial clear plexiglass cage $(10.5 \times 10.75 \times 20.5 \mathrm{~cm})$ with air holes in the lid. Test cages were securely stacked one on top of the other on the shaker table. Head and body movements were not restricted during the exposure to motion.

In addition to being observed diring the motion stimulus, animals were observed for a period of 1 min before and after the motion 
Vagotomy, CTA and Emesis

stimulus. Observations began $3 \mathrm{~min}$ after the 10-min drinking

opportunity of saccharin ended. Monitored behaviors were: (a) foot grooming, (b) face grooming, (c) licking, (d) genital grooming, (e) overall excitability, ( $f$ ) retching, ( $g$ ) gaping and $(h)$ vamiting. In order to enhance the reliability of behavioral observations animals were videotaped the entire time they were in the plexiglass cages. Animals were returned to their home cages immediately after the termination of motion and allowed continuous access to tap water for a 2-hr period. The testing cages were cleaned and deodorized after each test.

\section{Surgery}

Anesthesia was induced by placing shrews in a glass desiccating jar containing cotton soaked in Metaphane brand methoxyflurane. The animal remained in the jar for $3 \mathrm{~min}$. Once anesthetized, the shrew's abdomen was shaved using electric clippers. The shrew was monitored visually during this time to ensure it was still unresponsive, and if needed, a test tube filled with Metaphane-soaked cotton was placed over the animal's nose and mouth to maintain the anesthesia.

The shrew was then moved to a sterile surgery site and the animal's abdomen was disinfected by scrubbing with surgical Prep solution (ACU-dyne povidone-iodine U.S.P., 1\% iodine). During surgery anesthesia was closely monitored and Metaphane anesthetic was supplemented as needed.

Approximately a $1.2 \mathrm{~cm}$ incision was made from the xiphoid process toward the genitals. The skin was then loosened from the muscle tissue 
Vagotomy, CTA and Emesis

to facilitate suturing of the muscle and skin layers. After the skin was opened and loosened from the muscle, the muscle layer was opened with a slightly smaller incision than was made in the skin.

Forceps were used to retract the stomach, taking care not to damage other organs or to retract the stamach too far. Once the stamach was retracted, forceps were inserted underneath the esophageal-gastric junction to allow a clear view of the vagus nerve fibers. Methylene blue stain was applied to the site in order to stain the fibers of the vagus nerve.

Once the nerve fibers were identified, they were cut distal to the hepatic branch using a small pair of ophthaimic scissors. Care was taken to cut only those vagus fibers which travel to the stomach. The stomach was then repositioned in the peritoneal cavity and moistened with sucrose solution to aid the animal in recovery.

The muscle layer was closed with 6.0 Vicryl absorbable suture (Ethicon) using interrupted stitches. The skin layer was closed with 5.0 silk suture (Ethicon) using interrupted stitches. The finished sutures wore scrubbed with Tincture Merthiolate (1:1000) to discourage infection.

The animal was closely monitored during recovery. Frequent tactile stimulation and re-positioning on the sides and stomach was used to ensure that the animal did not choke due to fluid that might have been regurgitated or vamited. After the shrew began voluntarily crawling about the cage, it was retumed to the colony with continuous 
Vagotomy, CTA and Emesis

access to food and water.

Verification of Vagotomy

The completeness of vagotomy was assessed using an adaptation of the technique discussed by Fox and McKenna (1988) which measures gastric stasis. Since vagotomy affects the rate of stomach emptying, vagotomized animals should have food in their stomachs for a longer duration after eating than controls. Animals were fasted for a period of $12 \mathrm{hr}$ and then given a $30 \mathrm{~min}$ eating opportumity. The amount of food consumed was recorded for each animal. Four hours later, animals were anesthetized, their stomachs were removed and weighed, and stomach contents alone were weighed in order to determine if differences between groups in content weights existed. A ratio of how much food was eaten to how much food remained in the stamach was calculated. Vagotomy animals were expected to have significantly more food in their stomachs than controls that ate a comparable amount. Animals were euthanized by decapitation at the completion of the verification surgery.

Results

\section{Verification of Vagotomy}

Gastric stasis was used to assess the completeness of vagotony. Four different measures of gastric stasis were examined: (a) the amount of food eaten prior to the verification of vagotomy surgery was weighed to measure differences in food consumption between the Vagotomy Group and the Sham Group, (b) the weights of the stomachs (plus contents) were compared to assess differences between groups, (c) stomach content 
Vagotomy, CTA and Emesis

weights were compared to assess differences between groups, and (d) a ratio was computed comparing amount of food eaten before verification of vagotony surgery to amount of stomach contents remaining $4 \mathrm{hr}$ after consumption.

The amount of food eaten during the 30 min eating opportunity prior to the verification of vagotomy surgery was recorded to see if differences existed between the Sham Group and the Vagotomy Group in amount of food eaten. Detection of differences between groups was important to establish a baseline of food consumption for comparison of stomach contents later, or, if significant differences in food consumption were found between groups, to create a ratio of how much food was eaten to how much food remained in the stomach. No differences (Vagotony mean $=.89$, S.E. $=.07$; Sham mean $=.80$, S.E. $=.08$ ) were found between groups $[\underline{t}(10)=.82, \underline{p}>.05]$.

A t-test was used to examine if differences in stamach (plus contents) weights existed between the Sham Group and the Vagotamy Group (Vagotomy mean=.69, S.E. $=.11$; Sham mean=.54, S.E.=.17) No differences were found $[t(10)=1.17, p>.05]$.

Stomach contents were weighed to obtain a measurement of gastric stasis. A t-test was used to determine if gastric stasis differed between groups (Vagotomy mean=.23, S.E. $=.15$; Sham mean=.16, S.E. $=.04$ ). No differences between groups were found $[\underline{t}(10)=.47, \underline{p}>.05]$.

A ratio of amount of food eaten during the 30 min prior to verification of vagotony surgery to amount of stomach contents was 
Vagotomy, СTA and Emesis

calculated for each animal in the Sham and Vagotomy groups (Vagotany mean=24.75, S.E.=11.43; Sham mean=20.70, S.E.=5.27). No differences between groups were found $[\underline{t}(10)=.40, \underline{p}>.05]$, thus precluding any verification of the completeness of vagotany for animals in this experiment.

Tap Water Intake

A baseline tap water measurement was taken for 3 days prior to conditioning to evaluate whether there were initial consumption differences between groups. A 3(groups) x 3(days) mixed analysis of variance (ANOVA) with repeated measures on the second factor was used. The Vagotony Group, the Sham Group and the Control Group did not differ $[\underline{F}(2,15)=.07, \mathrm{p}=.93]$ in fluid intake before testing (Control mean=1.82, S.E.=.60; Sham mean=1.79, S.E.=.98; Vagotamy mean=1.93, S.E. $=.55$ ).

Tap water intake was examined to determine if the animais were drinking more, less, or the same amount of water across days. The results $[\underline{F}(2,30)=6.27, \underline{p}=.01]$ indicate an increase in the main effect for tap water consumption (Day 1 mean=1.59, S.E.=.19; Day 2 mean=1.98, S.E. $=.17$, Day 3 mean=1.97, S.E.=.15). Specific comparisons indicate that intake increased for Days 2 and 3 relative to Day $1(p=.01)$, but Days 2 and 3 did not differ $(p=.97)$. Animals may have drumk less on Day 1 because the situation was new or unfamiliar. No significant interaction between groups and days was detected $[\underline{F}(4,30)=2.11, p=.10]$. 
Vagotomy, CTA and Emesis

\section{Saccharin Intake}

A baseline saccharin measurement was examined prior to conditioning to ensure there were no differences in consumption across groups. A lack of difference in saccharin consumption across groups prior to testing was important for establishing a good baseline by which to compare saccharin consumption once it was paired with the motion stimulus. Although animals with vagotomy consumed the most saccharin on this test (Vagotany mean=3.20, S.E. $=.50$, Control mean=2.00, S.E. $=.63$, Sham mean $=2.50$, S.E. $=.53$ ), the amount consumed was not statistically different among the three groups $[\underline{F}(2,15)=1.22, \mathrm{p}=.32]$.

Saccharin intake on CTA test days was examined using a 3(groups) $\mathrm{x}$ 4(test days) ANOVA to determine if differences existed in saccharin consumption. Differences were expected across groups and days, since only the two control groups were expected to form a CTA and thus lower their saccharin intake. No statistically significant differences (Vagotomy mean $=2.72$, S.E. $=.21$; Sham mean $=1.58$, S.E. $=.29 ;$ Control mean $=1.23, S_{.}=.27$ ) were found among groups $[\underline{F}(2,15)=2.92, p=.09]$, but differences across days (Day I mean $=2.54$, S.E. $=.33$; Day 2 mean=2.01, S.E. $=.38$; Day 3 mean=1.45, S.E. $=.27$; Day 4 mean=1.38, S.E.=.28) reached significance $[F(3,45)=13.46, p=.01]$.

Since differences between groups approached, but did not reach, statistical significance and sample size was small ( $\underline{n}=6)$, saccharin intake on CTA test days was re-assessed as a percentage of intake prior to conditioning. The raw data (see Figure 1), saccharin consumption in 
Vagotomy, CTA, and Emesis

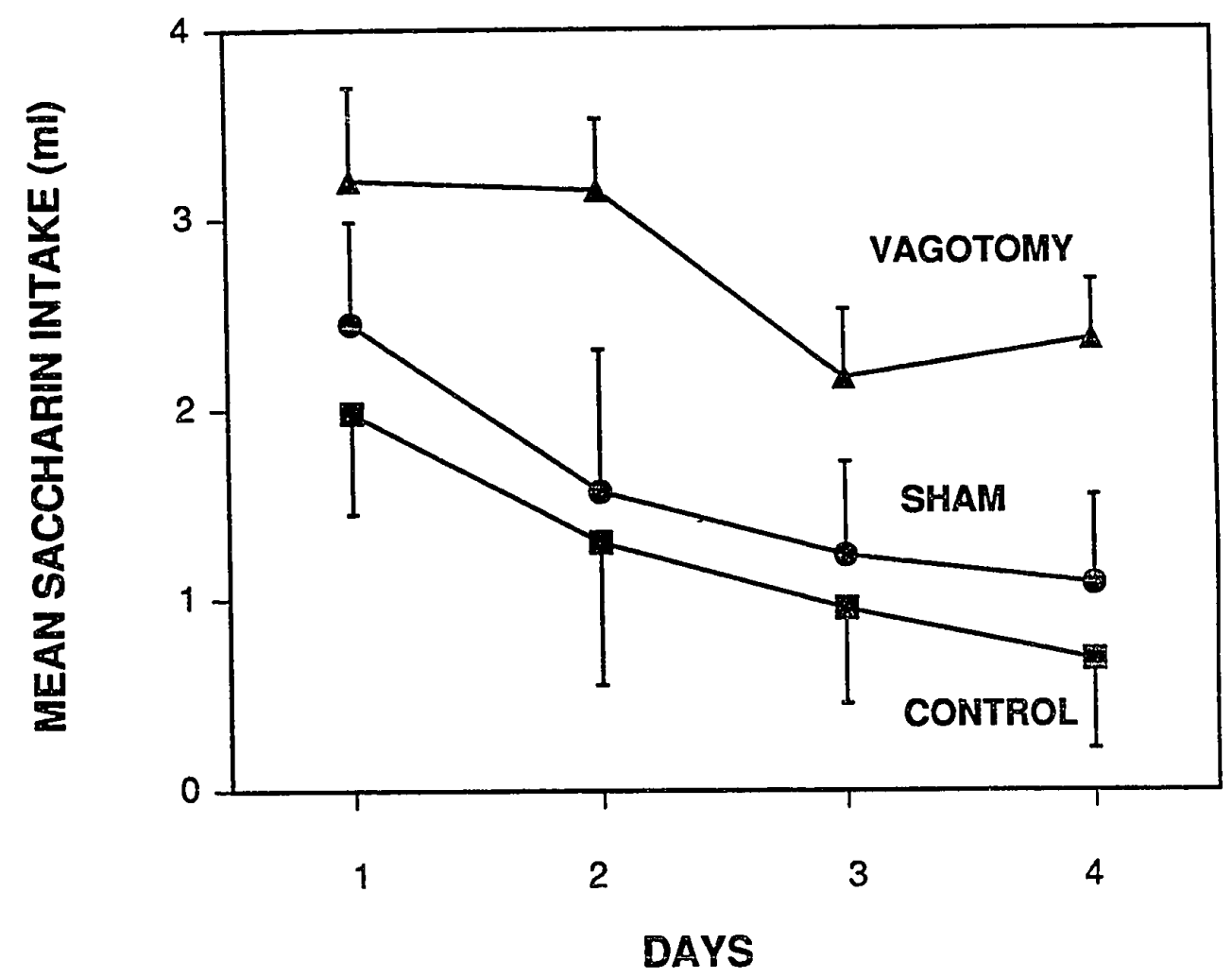

Figure 1. Mean intake (with S.E. bars) of saccharin flavored water ( $\underline{n}=6$ per group) on the 3 conditioning days (Days 1-3) and on the final test day (Day 4) when the animals were not exposed to motion. 
Vagotomy, CTA and Emesis

$\mathrm{ml}$, on the three saccharin test days was converted to a percentage of the initial baseline saccharin intake measurement. This was done to correct for individual variability in consumption before conditioning. Again, significant differences were expected between groups and groups $\mathrm{x}$ days.

In this percentage analysis, there were differences in consumption among groups $[F(2,15)=5.93, \underline{p}=.01]$. A planned comparison was employed to compare the Control and Sham Groups to the Vagotomy Group. Animals in the two control groups drank less of the saccharin solution than those in the Vagotomy Group $(p=.01)$, indicating the Vagotomy Group may not have formed a CTA as did controls (Control mean=.33, S.E.=.08; Sham mean $=.43$, S.E. $=.08$; Vagotomy mean $=.88, \mathrm{~S} . \mathrm{E} .=.08$ ) Consumption across days was examined to determine if the animals decreased consumption after conditioning (Day 1 mean=.70, S.E.=.11; Day 2 mean=.50, S.E.=.09; Day 3 mean=.44, S.E.=.09). Significant differences in consumption across days were also found $[\underline{F}(2,30)=6.35$, $\mathrm{p}=.011$. Post hoc comparisons revealed that animals drank more on Day $I$ than on either Day $2(p=.01)$ or Day $3(p=.01)$ but that Days 2 and 3 did not differ $(p=.48)$. This effect was attributed to the formation of a CTA by the controls and shams, since their overall consumption total should be lower. No interaction between groups and test days was found $[\underline{F}(4,30)=.30, p=.88]$.

A one-way repeated measures ANOVA was conducted to determine if the vagotomiy shrews drank less of the saccharin solution across days 
Vagotomy, CTA and Emesis

(See Figure 2). Decreased consumption across days indicated that the Vagotorny Group did form an aversion $[F(2,10)=5.11, p=.03]$. A post hoc comparison showed that the Vagotony Group drank more on test Day 1 versus test Days 2 and $3(p=.01)$, but did not differ in how much they drank between Day 2 and Day $3(p=.76)$. The Vagotomy Group reduced saccharin intake on Days 2 and 3 in relation to Day 1 , indicating the formation of an attenuated aversion to the saccharin solution. The Control Group and Sham Group did not significantly reduce the amount of saccharin consumed across days, since their consumption was already low due to the formation of a CTA.

Retch/Vomit Episodes.

During conditioning, the number of retches and vanits in response to motion was recorded for each animal (See Figure 3). A 3 (groups) $\times 3$ (days) ANOVA was conducted to evaluate effects on the incidence of retching and vomiting. There were no significant differences between groups $[\underline{F}(2,15)=2.25, p=.14]$, but the frequency of retch/vomit incidence decreased $[\underline{F}(2,30)=6.46, \underline{p}=.01]$ across days, (Day 1. mean=5.56, S.E. $=1.85$; Day 2 mean=3.78, S.E. $=1.39 ;$ Day 3 mean=3.17, S.E. $=1.14$ ). The vagotomy surgery had no effect on retch/vomit episodes. All animals tended to retch and vomit less as they habituated to the motion stimulus. Animals retched and vomited more on Day 1 than on Day 2 $(p=.02)$ or Day $3(p=.01)$. Retching and vamiting did not differ between Day 2 and Day $3(p=.38)$. 
Vagotomy, CTA and Emesis

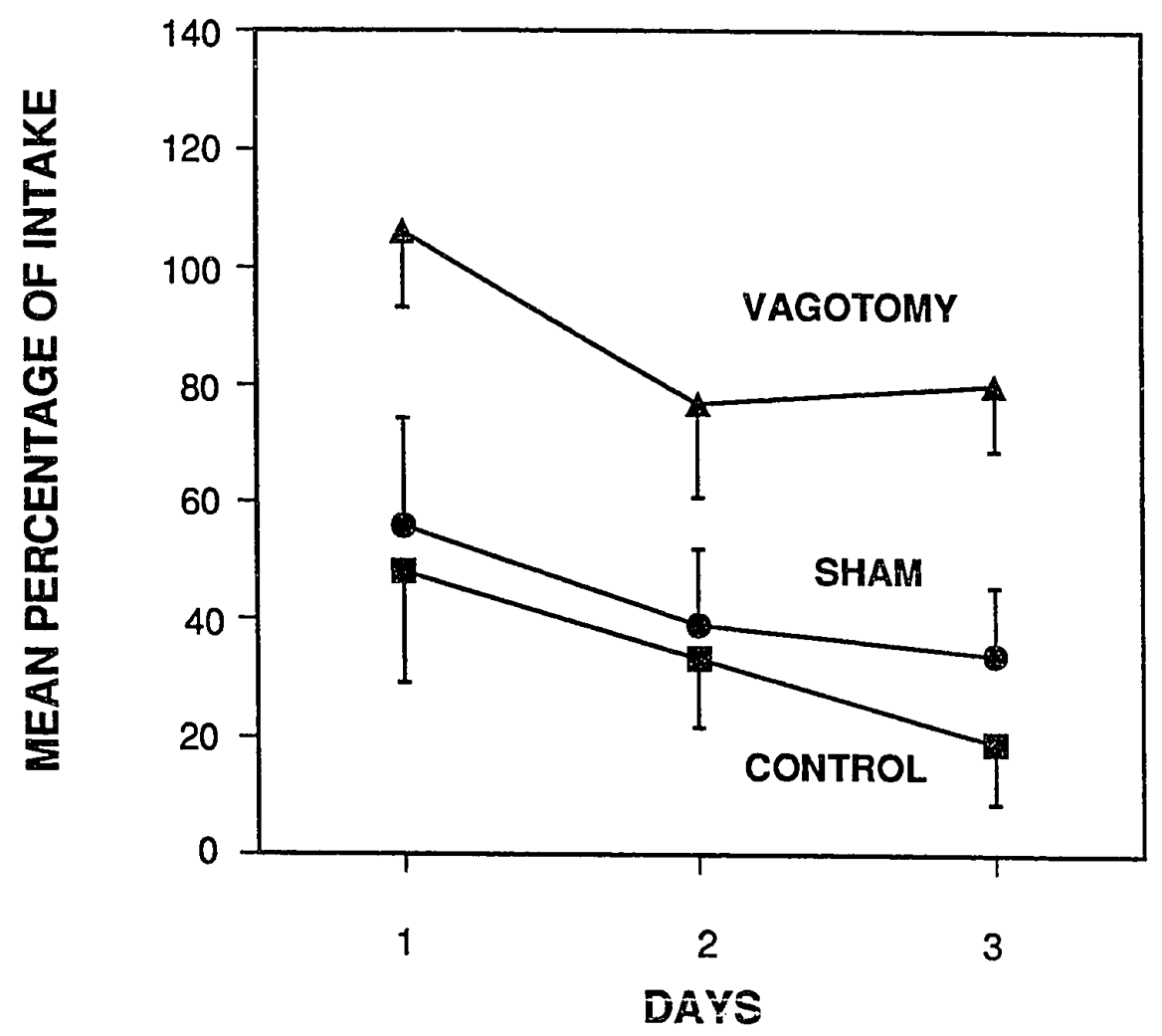

Figure 2. Mean intake (with S.E. bars) of saccharin flavored water ( $n=6$ per group) on the 3 days foliowing exposure to motion (Days 2-4) expressed as a percentage of intake on the first day (Day 1). 
Vagotomy, CTA and Emesis

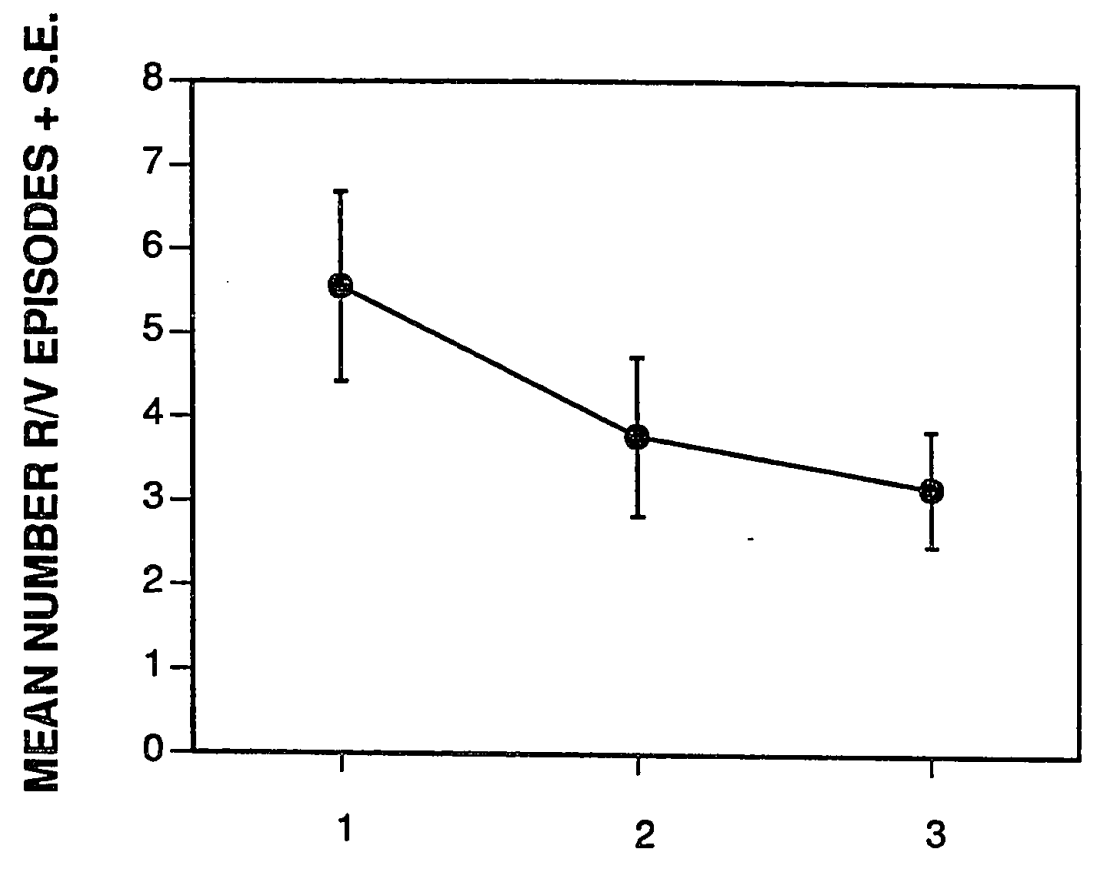

TEST DAY

Figure 3. Mean number of retching/vomiting episodes ( $n=6$ per group) on each of the three test days. 
Vagotomy, CTA and Emesis

Discussion

The main purpose of this experiment was to examine whether the vagus nerve crucially madiates both motion-induced CTA and motioninduced emesis. Some evidence in this experiment indicated that vagotomy attenuated or delayed motion-induced CTA. However, no evidence indicated that vagotomy affected motion-induced emesis. This experiment, evaluated in the light of prior research, supports the notion that the vagus nerve contributes to the formation of motioninduced CTA, but not to motion-induced vomiting. This result could support the notion that motion-induced CTA and motion-induced vamiting are crucially mediated by separate neural pathways, or could utilize additional neural systems. It is still unknown, however, whether the general function of the vagus is one of stimulus-response mediation or neural modulation.

The fact that CTA was not completely blocked as in the Fox and McKenna (1988) study could be due to species differences or procedural differences. One problem in the current experiment was in the verification procedure for complete vagotomy. This may have allowed same animals with incomplete vagotomies to be included in the experiment. Such animals would be expected to act more like controls and form a CTA to the solution, obscuring the aversion effects of complete vagotomy and diluting statistical analyses.

The discrepant findings between this study and Fox and McKenna (1988) may be a species-related effect. It is possible that the shaker 
Vagotomy, СТA and Emesis

table type of motion stimulus is a more provocative stimulus for shrews than vertical axis rotation is for the rat. Species-specific differences in motion sickness susceptability have been previously descibed, with some species being more susceptible than others to different types of motion (Daunton, 1990). For example, rotation seems to be the best stimulus to produce motion sickness in rats and squirrel monkeys. For dogs, however, the swing is the most effective stimulus for producing motion sickness, and for cats the stimulus of choice is vertical oscillation. This study, as well as past research, provides some support for the notion that shrews may be more sensitive to shaker table motion than other types of motion (Ueno et al., 1988).

In the current study, it was observed that shrews exposed for intervals of only $5 \mathrm{~min}$ to shaker table motion elicited numerous episodes of retching and vamiting. Prior pilot studies conducted in this laboratory using centrifuge type motion produced very little retching and vomiting from shrews, even when exposed for up to $2 \mathrm{hr}$. Had the Fox and McKenna (1988) study used a more provocative stimulus for the rat, they may have found attienuated, rather than biocked CTA, because a stronger stimulus should produce a more pronounced CTA.

The fact that vomiting episodes were not reduced by vagotomy in this study as they were in the Wang et al. (1957) study was an unexpected finding. Since the Wang study used dogs, it is possible that this discrepancy is attributable to a species difference between the dog and the shrew. It is also possible, however, that the inability to 
Vagotomy, CTA and Emesis

verify the completeness of vagotomy in each shrew contributed to the different results, since incomplete vagotomy may have diluted the aversion effect of complete vagotony.

It is interesting to note that the gastric stasis measurement used to verify vagotomy in rats (Fox \& McKenna, 1988) did not work in this experiment with shrews. Most of the shrews had extremely small amounts of food, if any, remaining in their stomachs. The lack of stomach contents may be related to the high metabolic rate associated with this insectavore, or perhaps other procedural variables such as the digestability of the cat chow.

The fact that the Vagotomy Group animals still retched and vomited after vagotany could be taken as an indication that vagotomy does not affect the ability to become motion sick. This implies that CTA may not be critically related to "internal malaise," and detracts from the theory that CTA provides an accurate assessment of nausea in animals which do not vomit (Garcia et al., 1985; Brizzee et al., 1980; Roy \& Brizzee, 1979).

Consistent with prior results (Ueno et al., 1988), the shrews habituated quite quickly to motion. Based on this experiment alone, it cannot be deduced that vagotomy affects the rate of this habituation. It is, however, an excellent area of study for future research. In general, the shrews decreased the number of retch/vomit indices over trials, indicating that the motion stimulus was being perceived as a weaker and weaker stimulus to the shrews. This seenis counter to the 
Vagotomy, CTA and Emesis

results, however, since in general CTA became stronger on subsequent trials. This logic makes it seem unlikely that the Vagotomy group formed a delayed, rather than attenuated, CTA.

The results of this experiment supported the first research hypothesis that $\mathrm{Hl}$ : the formation of a motion-induced CTA is attenuated by vagotomy, but did not support the second hypothesis that H2: the proportion of animals that vomited differed between the Vagotomy group and the two control groups. Thus, it appears the vagus nerve in suncus murinus is a critical neural pathway in the mediation of motion-induced CTA, but is less important in the mediation of motion-induced emesis. 
Vagotomy, CTA, and Emesis

\section{References}

Bernstein, I. L., \& Webster, M. M. (1980). Learned taste aversions in humans. Physiology \& Behavior, 25, 363366 .

Brizzee, K. R., Ordy, J. M., \& Mehler, W. R. (1980). Effect of ablation of area postrema on frequency and latency of motion sickness-induced emesis in the squirrel monkey. Physiological Behavior, 24, 849-853.

Coil, J. D., Rogers, R. C., Garcia, J., \& Novin, D. (1978). Conditioned taste aversions: Vagal and circulatory mediation of the toxic unconditioned stimulus. Behavioral Biology, 24, 509-519.

Corcoran, M., Fox, R., Brizzee, K., Crampton, G., \& Daunton, N. (1985). Area postrema ablations in cats: Evidence for separate neural routes for motion- and xylazineinduced CTA and emesis. Physiologist, 28, 330-335.

Daunton, N. G. (1990). Animal models in motion and space sickness research. In G.H. Crampton (Eds.), Motion and Space Sickness. (pp.87-104). Boca Raton: CRC Press.

Dragoin, W., McCleary, G. E., \& McCleary, P. (1971). A comparison of two methods of measuring conditioned taste aversions. Behavioral Research Methods and Instrumentation, $3,309-317$.

Fox, R., Corcoran, M., \& Brizzee, K. R. (1988). Conditioned taste aversion and motion sickness in cats and squirrel monkeys. Canadian Journal of Physinlogy and Pharmacology, 68, 269-278.

Fox, R., \& McKenna, S. (1988). Conditioned taste aversion induced by motion is prevented by selective vagotomy in the rat. Behavioral and Neural Biology, 50, 275-284.

Gamzu, E. (1977). The multifaceted nature of taste-aversion inducing agents: Is there a single common factor? In: Barker, L., Best, M. , \& Domjan, M. (Eds.) Learning Mechanisms in Food Selection. Waco: Baylor University Press. 
Vagotomy, CTA, and Emesis

Garcia, J., Kimeldorf, D. J., \& Hunt, E. L. (1961). The use of ionizing radiation as a motivating stimulus. psychological Review, 68, 383-395.

Garcia, J., Lasiter, P. S., Bermudez-Rattoni, F., \& Deems, D. A. (1985). A general theory of aversion learning. Annals of the New York Academy of Sciences, 443, 8-21.

Gerstner, H. B. (1960). Reaction to short-term radiation in man. Annual Review of Medicine, 11, 289-302.

Grant, V. L. (1987). Do conditioned taste aversions result from activation of emetic mechanisms? Psychopharmacology, 93, 405-415.

Graybiel, A., Wood, C. D., Miller, E. F., \& Cramer, D. B. (1968). Diagnostic criteria for grading the severity of acute motion sickness. Aerospace Medicine, 39, 453455 .

Grote, R. W., \& Brown, R. T. (1971). Conditioned taste aversions: Two-stimulus tests are more sensitive than one-stimulus tests. Behavioral Research Methods and Instrumentation, $3,311-316$.

Hartley, P. L. (1977). Motion-induced learned taste aversions in rats and the role of the area postrema. Dissertation Abstracts Int, 38:2925B.

Hatcher, R. $\bar{A}$. ( 1924 ). The mechanism of vomiting. Physiological Review, $4,479-483$.

Ossenkopp, K.-P., \& Ossenkopp, M. D. (1985). Animal models of motion sickness: Are nonemetic species an appropriate choice? The Physiologist, 28, s61-s62.

Powley, T. L., Prechtl, J. C., Fox, E. A., \& Berthoud, H. -R. (1983). Anatomical considerations for surgery of the rat abdominal vagus: Distribution, paraganglia, and regeneration. In J. G. Kral, T. L. Powley, \& C. McC. Brooks (Eds.), Vagal Nerve Function: Behavioral and Methodological Considerations. (pp. 79-97). New York: Elsevier Science.

Prasad, K. N. (1984). CRC Handbook of Radiobiology. Boca Raton: CRC Press. 
Vagotomy, CTA, and Emesis

Rabin, B. M., Hunt, W. A., \& Lee, J. (1985). Intragastric copper sulfate produces a more reliable conditioned taste aversion in vagotomized rats than in intact rats. Behavioral and Neural Biology, 44, 364-373.

Roy, A., \& Brizzee, K. R. (1979). Motion sickness-induced food aversions in the squirrel monkey. Physiology and Behavior, 23, 39-41.

Ueno, S., Matsuki, N., \& Saito, H. (1987). Suncus murinus: A new experimental model in emesis research. Life Sciences, 41, 513-518.

Ueno, S., Matsuki, N., \& Saito, H. (1988). Suncus murinus as a new experimental model for motion sickness. Life Sciences, $43,413-420$.

Wang, S. C., \& Borison, H. L. (1951). Copper sulfate amesis: A study of afferent pathways from the gastrointestinal tract. American Journal of Physiology, 164, 520-526.

Wang, S. C., Chinn, H. I., \& Renzi, A. A. (1957). Experimental motion sickness in dogs: Role of abdominal visceral afferents. American Journal of Physiology, $190,578-580$.

Wilpizeski, C. R., \& Lowry, L. D. (1987). Area postrema ablation and subjective concomitants of rotationinduced sickness in squirrel monkeys. Aerospace Medical Association Abstract, Alo. 